Doi: $\underline{\mathrm{dx} . \text { doi.org/10.17921/2525-5320.2016.46-51 }}$

\title{
PASTORAL DA SAÚDE E BIOÉTICA: ELEMENTO PLASMÁTICO NA FORMAÇÃO DO NOVO HOMEM NA ASSISTÊNCIA À SAÚDE
}

\author{
Natacha Bolorino* - Mater Ter Admirabilis \\ Tatiane Angélica Phelipin Borges* - Mater Ter Admirabilis \\ Elvira Maria Perides Lawand* - Mater Ter Admirabilis
}

Palavras-chave: Biopsicossocial. Pedagogia de Schoenstatt. Pastoral da Saúde e Bioética.

\section{INTRODUÇÃO}

$\mathrm{Na}$ trajetória de desenvolvimento evolutivo das concepções de assistência à saúde, encontra-se inserido predominantemente o modelo biomédico, que estimula os profissionais da saúde à prestarem um atendimento fragmentado, isto é, dando atenção apenas as partes que irão receber o cuidado, dificultando a atenção como um ser humano completo. Deste modo, mesmo que os profissionais tenham interesse na aplicabilidade da assistência holística, acabam por regredir ao reducionismo, pois este modelo foi inserido durante o seu período de formação educacional (BARROS, 2002).

O modelo referido em questão causa insatisfação tanto nos profissionais quanto nos usuários da assistência à saúde. Devemos reconhecer que o usuário tem necessidades que vão além de biológicas, que deve-se considerar elementos psicológicos e sociais que se envolvem o processo saúde-doença-cuidado, integrando-se no contexto da qualidade do nível de assistência prestada. Esta visão perante o indivíduo, significa tornar-se humano.

Atualmente, as instituições que prestam assistência à saúde conceituam o ser humano como alguém que não se reduz apenas às necessidades biológicas, mas como um ser humano biopsicossocial e espiritual, com direitos a serem respeitados, devendo ser garantida sua dignidade ética, é imprescindível para caminharmos ao êxito da assistência à saúde (BARBOSA, 2007).

\footnotetext{
*E-mail: natachabolorino@hotmail.com

*E-mail: tatiphelipini@hotmail.com

*E-mail: diretoria.cepmta@iscal.com.br
} 
Frente ao exposto, há um direcionamento das necessidades de atuação profissional daqueles que irão atuar na prática profissional. À partir deste direcionamento, consideramos a humanização como estratégia de intervenção na atuação profissional.

Sob esta ótica de direção, os agentes da construção dos saberes acerca da prática profissional, temos o docente que assume o papel de educador e transmissor do conhecimento e ao mesmo tempo mediador. Isto é, o docente atua como ponte entre o discente e o conhecimento, para que ele possa obter uma percepção crítica e reflexiva sobre as suas práticas e não mais receba passivamente as informações como se fosse um reservatório de informações depositadas pelo educador (BULGRAEN, 2010).

Os saberes na construção das competências profissionais, prioritariamente significa reconhecer que as relações do mundo sofrem mudanças e que a formação profissional precisa acompanha-las (DOMENICO, 2005).

Nesta perspectiva, as pessoas humanas só poderão conduzir a ação se reconhecerem que a transformação se encontra neles mesmos e se tiverem conhecimento do que foi vivenciado no seu período de formação (FRANCO, 2003).

Desde já, adotamos a humanização como método de mediação para repensar em uma prática de saúde que considere os sujeitos sociais, quando estimulados são capazes de coletivamente serem responsáveis pelas transformações de realidades, acolhendo os usuários e favorecendo o seu protagonismo enquanto constituinte do sistema de saúde (BENEVIDES, 2005).

A formação profissional promovida no Centro de Educação Profissional Mater Ter Admirabilis (CEPMTA) segue ao encontro das necessidades do modelo de atenção à saúde, exercendo a Pedagogia de Schoenstatt, que está voltada à formação do ser humano integral, favorecendo o desenvolvimento intelectual, biopsicossocial, religioso, afetivo e ético da pessoa humana (PROJETO POLÍTICO PEDAGÓGICO, 2015).

A Pedagogia de Schoenstatt se deu juntamente com o Movimento Internacional de Schoenstatt que surge como um movimento religioso, desta forma, ambos se concretizaram e são tratados como unidade, levantando as duas bandeiras: religiosa e educacional.

O fundador da Obra de Schoenstatt, Pe. José Kentenich, idealiza uma instituição educacional que transmita os valores religiosos-morais para formar homens novos 
para uma comunidade nova por meio da educação católica, com referência em Jesus e Maria, ou seja, uma instituição fundamentada no modelo de educação cristomariana (ALVILLA, 2011).

Reiterando a formação do ser humano integral, o CEPMTA tem como meta primordial a formação do novo homem na nova comunidade. Segundo ressaltado pelo Padre Kentenich em seu livro, o Deus Vivo necessita de instrumentos para facilitar o trabalho dos educadores, nos mostrando como modelo: a Mãe de Deus, a educadora dos povos, que em Schoenstatt é venerada como a Mater Ter Admirabilis (Mãe Três Vezes Admirável). Com a sua constituição por Deus como tal, não temos dificuldade em assimilar a idéia de educadora ligada à mãe, pois ser mãe quer dizer educadora em todo o sentido (KENTENICH, 1984, p.27).

O fundador ainda descreve que, a grande missão que Maria tem na área pedagógica: "Consideramos a Sma. Virgem como a grande solução para as necessidades e problemas da pastoral e da pedagogia de hoje. Só há uma coisa a fazer: entregar-nos sem reserva a Ela, entregra-nos e entregar os que nos foram confiados à Bendita entre todas as mulheres" (STRADA, 1998).

Frente ao exposto, o Centro de Educação Profissional, possui um diferencial que acreditamos ser um elemento plasmático na formação do educando, para que ele possa se formar um novo homem e atender as expectativas em questão.

Durante a jornada de moldagem profissional, o educando passa por períodos, sendo estes, denominados módulo I, módulo II e até mesmo módulo II que somarão como requisitos para obter sua certificação profissional.

Neste sentido, todos os discentes que nos confiaram sua formação profissional, passam por uma disciplina denominada Pastoral da Saúde, que está inclusa em sua grade curricular por todos os módulos do curso, mantendo um elo entre as disciplinas teóricas e práticas acerca dos saberes pertinentes à área de atuação e a disciplina que os formarão para que sejam um novo homem.

Para abranger e acompanhar todo o período de formação do educando, esta mesma se fragmenta em três partes sendo assim denominada: Pastoral da saúde, Ética Profissional e Pastoral da Saúde e Bioética e Pastoral da Saúde, no primeiro, segundo e terceiro módulo respectivamente.

A Pastoral da Saúde da nossa instituição formadora acredita no amor e na justiça, baseados nos princípios do cristianismo, tendo como modelo a Maria, a Mãe e Rainha, Educadora por meio do seu Santuário de graças (PROJETO POLÍTICO 
PEDAGÓGICO, 2015).

Ressignificando o saber sobre o modelo de assistência à saúde, isto é, atender o enfermo como um ser humano integral. Segundo Durães (2011), a Pastoral da Saúde compreende que o ser humano integral possui quatro dimensões: a dimensão física, mental, social e espiritual. Só quando todas as dimensões são contempladas é que se pode pensar num bem-estar integral.

No ensino do educando em seu primeiro módulo do curso, para introduzi-lo aos ensinamentos para a formação do novo homem na comunidade, são ministrados conteúdos acerca da conceitualização da Pastoral da Saúde, contextualização e aplicação nos contextos de saúde com direcionamento aos desígnios de Deus em relação ao homem, mandamentos da Lei de Deus e Sacramentos.

A Pastoral da Saúde está inserida no contexto onde exista um indivíduo que requer cuidados à sua saúde e um profissional que prestará a assistência. Desta maneira, a Pastoral, guiada pela luz do Evangelho, oferece auxílio para os profissionais que atuam na saúde, expondo-lhes que a técnica deve ser acrescida com a ternura do cuidado e que esta pode aliviar o sofrimento e até mesmo torná-lo suportável, promovendo conforto e esperança, uma assistência que visa a compaixão que se desprende de si para estar ao lado do outro que sofre (MARTINS, 2010).

Já no segundo módulo, para os discentes prosseguirem o seu desenvolvimento pessoal e profissional, esta inserido na ementa da disciplina denominada Ética Profissional e Pastoral da Saúde que contribuirá para a atuação profissional no âmbito da Ética, fazendo exposição do tema, debates e discursos acerca de como os educandos deverão se conduzir profissionalmente e proceder o bem sem que haja prejuízo ao próximo. Todos estes valores serão acrescidos da Pastoral, cujo módulo exerce o papel de fortalecer os ensinamentos obtidos no módulo anterior, fazendo um direcionamento para a formação da própria personalidade de acordo com seus ideais ou missão de cada um.

A educação tem um poderoso papel, pois o indivíduo de hoje, será o indivíduo de amanhã, sendo assim, nos foi confiada a valiosa atribuição da formação dos futuros profissionais que atenderão a humanidade. Cabe à educação desempenhar os objetivos sociais que a ela são atribuídos e além disso, reconhecer sua finalidade, refletir sobre o papel em que se deve assumir, e a maneira como deve ser direcionada as suas ações. Sendo assim, os formadores das futuras gerações devem oferecer o ensino que atue como agente da mudança, no qual não se reduz apenas a uma etapa 
da vida, mas que este possa se dissipar de maneira permanente no seu ambiente de trabalho (SCHIMDT, 2008).

Ainda nesta linha de aprendizado, o educando recebe uma última dose deste elemento plasmático, antes que se torne egresso de nossa instituição e pronto para o mundo de trabalho. Trata-se de uma retomada de todos os ensinamentos de Pastoral obtidos nos módulos anteriores, acrescidos dos proveitosos ensinamentos acerca da Bioética.

Neste sentido, o ensinamento de Bioética constitui para o educando um meio de elaboração subjetiva no qual ele desenvolve de maneira representativa o sentido de sua vida e modo de agir, com base na vulnerabilidade desencadeada por situações que apontam para a fragilidade da vida humana (SELLI, 2007).

\section{CONCLUSÃO}

As transformações da assistência à saúde remetem um direcionamento para o profissional, e a formação profissional deve caminhar juntamente com os avanços do mundo de trabalho para que atenda as expectativas depositadas.

Em contrapartida ao modelo de assistência denominado biomédico, temos o modelo biopsicossocial que se executa com humanização sendo uma ferramenta primordial. Para tanto compreendemos a essencialidade deste modelo inserido durante o período de formação, sendo executado como um elemento plasmático dosado em todas as etapas do seu processo de formação.

Dentro deste contexto o nosso Centro de Educação Profissional, além de promover uma formação lapidada com as transformações do mundo através da disciplina Pastoral da Saúde, seguimos a Pedagogia de Schoenstatt fundamentada pelo padre José Kentenich, cujo deixou para nós seus discípulos, o legado de que sem uma pedagogia de amor não há educação fecunda e duradoura pautada na missão que a Maria tem na Educação.

Com base na responsabilidade social que a nossa instituição apresenta, esperase que o discente aproprie-se da relevância da disciplina Pastoral da Saúde E Bioética, bem como possa aderir os ensinamentos e os coloque em prática para a sua vida pessoal e profissional, sendo assim, estamos caminhando na direção da melhoria da assistência à saúde. 


\section{REFERÊNCIAS}

ALVILA, A.F. Concepção de educação e escola expressa na obra "Linhas Fundamentais de uma pedagogia moderna para o educador Católico": Padre José Kentenich (1885-1968). 2011. 64 p. Trabalho de Conclusão de Curso (Pedagogia) Universidade Estadual de Londrina. Londrina, 2011.

BARBOSA, I.A; SILVA, J.P.S. Cuidado humanizado de enfermagem: o agir com respeito em um hospital universitário. Rev. Bras. Enferm.,v.60, n.5, p.546-551, 2007.

BARROS J.A.C. Pensando o processo saúde doença: a que responde o modelo biomédico?. Saúde Soc., v.11, n.1, p.67-84, 2002.

BENEVIDES, R.; PASSOS, E. Humanização na saúde: um novo modismo?. Interface Comunic, Saúde, Educ, v.9, n.17, p.389-406, 2005.

BULGRAEN, V.C. O papel do professor e sua mediação nos processos de elaboração do conhecimento. Rev. Conteúdo, v.1, n.4, 2010.

CENTRO DE EDUCAÇÃO PROFISSIONAL MATER TER ADMIRABILIS, Projeto Político Pedagógico. Irmandade Santa Casa de Londrina - Educação Profissional Técnica na Área da Saúde. Londrina - PR, 2015.

DOMENICO, E.B.L.; IDE, C.A.C. Referências para o ensino de competências na enfermagem. Rev. Bras. Enferm. v.58, n.4, p.453-457, 2005.

DURÃES, J.S.; SOUZA, W. A Pastoral da Saúde e sua importância no mundo da saúde: da presença solidária ao transcender a dor e o sofrimento. In: CONGRESSO DE HUMANIZAÇÃ̃O, 2; e JORNADA INTERDISCIPLINAR DE HUMANIZAÇÃO, 1. 2001, Curitiba.

FRANCO, T.B; MERHY, E.E. O uso de ferramentas analisadoras para apoio ao planejamento dos serviços de saúde: o caso do serviço social do hospital das clínicas da Unicamp. In: MERHY, E.E. et al. O trabalho em saúde: olhando e experienciando o SUS no cotidiano. São Paulo: Hucitec, 2003. p.135-160.

KENTENICH, P.J. Linhas fundamentais de uma pedagogia moderna: para o educador católico. Santa Maria: Movimento Apostólico de Schoenstatt,1984.

MARTINS, A.A. A Pastoral da Saúde e sua importância no mundo da saúde: da presença solidária ao transcender a dor e o sofrimento. O Mundo da Saúde, v.34, n.4, p.547-552, 2010.

SCHIMDT, I.T.; LUSSARI, W.R. Educação de adultos: os cursos de formação profissionalizante: uma alternativa para o exercício global de cidadania. Estudos Sobre Educação, v.15, n.16, p.175-185, 2008.

SELLI, L.; ALVES, J.S. O cuidado espiritual ao paciente terminal no exercício da enfermagem e a participação da bioética. Bioéthikos, v.1, n.1, p.43-52, 2007.

STRADA, A. Maria: um exemplo de mulher. Ave Maria, 1989 